\title{
RETROPERITONEAL EXTRAOSSEOUS EWING'S SARCOMA WITH RENAL INVOLVEMENT: US AND MRI FINDINGS
}

\author{
ANDRÉ THEBERT, MD, ISAAC R. FRANCIS, MD, AND \\ RICHARD A. BOWERMAN, MD
}

A case of retroperitoneal extraosseous Ewing's sarcoma (EES) with renal involvement, which simulated an exophytic renal mass, is reported. EES is a rare soft tissue tumor that can occur anywhere in the soft tissues, but is seen most commonly in the extremities. Although EES is histologically similar to osseous Ewing's sarcoma, it is usually found in older patients. EES should be included in the differential diagnosis of soft tissue tumors, especially in the second and third decade of life.

\section{KEY WORDS:}

Ewing's sarcoma; Extraosseous; Ultrasound; Magnetic resonance imaging

\section{INTRODUCTION}

Extraosseous Fwing's sarcoma (EES) is a rare tumor first reported by Tefft in 1969 and further characterized by Angervall and Enzinger in 1975 (1-3). It has been reported in the chest, abdomen, pelvis, and extremities $(4,5)$. In the retroperitoneum, EES commonly is found in a paraspinal location (4-6). We present a case of a 22-year-old G2P1 woman who presented with abdominal pain during the third trimester of her pregnancy. Ultrasonography (US) and magnetic resonance imaging (MRI) were performed on the day of admission. These results, along with the surgical and pathological correlation, form the basis of this report.

From the Department of Radiology, University of Michigan Hospitals, Ann Arbor, Michigan.

Address reprint requests to: Isaac R. Francis, MD, Box 30, Department of Radiology, University of Michigan Hospitals, 1500 E. Medical Center Drive, Ann Arbor, MI 48109-0030.

Received August 1992; accepted October 1992.

(C) 1993 Elsevier Science Publishing Co., Inc.

655 Avenue of the Americas, New York, NY 10010

0899-7071/93/\$6.00

\section{CASE REPORT}

A 22-year-old woman (G2P1) with a gestational age of 29 weeks complained of a one-month history of back pain with sharp right upper quadrant pain three days prior to admission. The patient's hematocrit had dropped from 38 to $30 \%$ over the previous four months. Other laboratory data were within normal limits. Physical examination revealed a right upper quadrant mass with tenderness in the mid-epigastrium.

Ultrasonography demonstrated a large right retroperitoneal mass involving the upper pole of the right kidney (Figure 1). It was a predominantly cystic, thick walled, and septated mass containing particulate matter felt to most likely represent hemorrhage in light of the patient's history (Figures 2 and 3). Solid components were noted caudally, adjacent to and blending with the kidney, felt to be consistent with tumor or possibly clot (Figure 3). A tissue plane was seen between the mass and the liver, indicating that it was not of hepatic origin.

MRI was performed using SE T1 and T2 weighted axial images, supplemented with T1-weighted coronal images. Imaging parameters for the T1-weighted axial images were: $\mathrm{TR}=500 \mathrm{msecs}$, and $\mathrm{TE}=30 \mathrm{msecs}$, $256 \times 256$ matrix, 4 NEX and scan thickness was 10 $\mathrm{mm}$ with no interslice gap. For the T2-weighted images the parameters were: $\mathrm{TR}=2000$ msecs, $\mathrm{TE}=30 / 60$ msecs, $256 \times 256$ matrix, 2 NEX, and scan thickness was $10 \mathrm{~mm}$ with an interslice gap of $1 \mathrm{~mm}$.

MRI revealed a well circumscribed $18 \times 15 \times 22$ $\mathrm{cm}$ mass contiguous with the upper pole of the right kidney (Figure 4). A clear plane of separation was seen between the mass and the liver. The right adrenal gland could not be identified. On the T1-weighted images, the mass was of low signal intensity with areas of high signal intensity seen on the T2-weighted images corresponding to the fluid filled cystic spaces demon- 


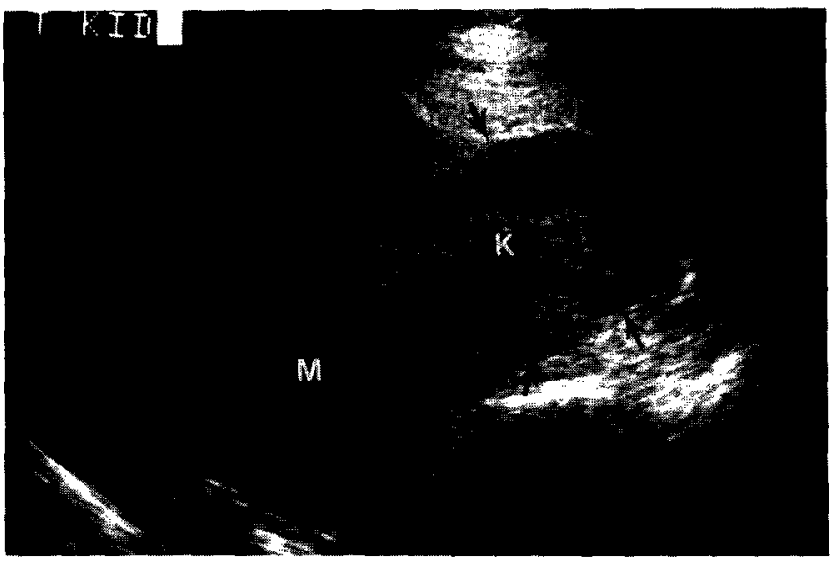

FIGURE 1. Sagittal section of right upper quadrant ultrasound demonstrates the large mass (M) that involves the upper pole of the right kidney ( $\mathrm{K}$, arrows).

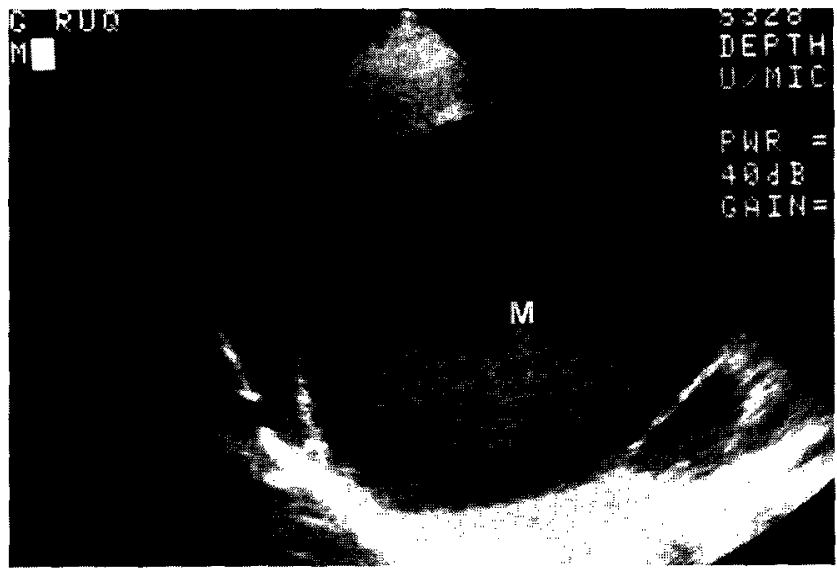

FIGURE 2. Sagittal section of right upper quadrant ultrasound demonstrates the cystic component of the mass (M) with echogenic material within.

FIGURE 3. Sagittal section of right upper quadrant ultrasound demonstrates septation and solid component of the mass (M, arrows).

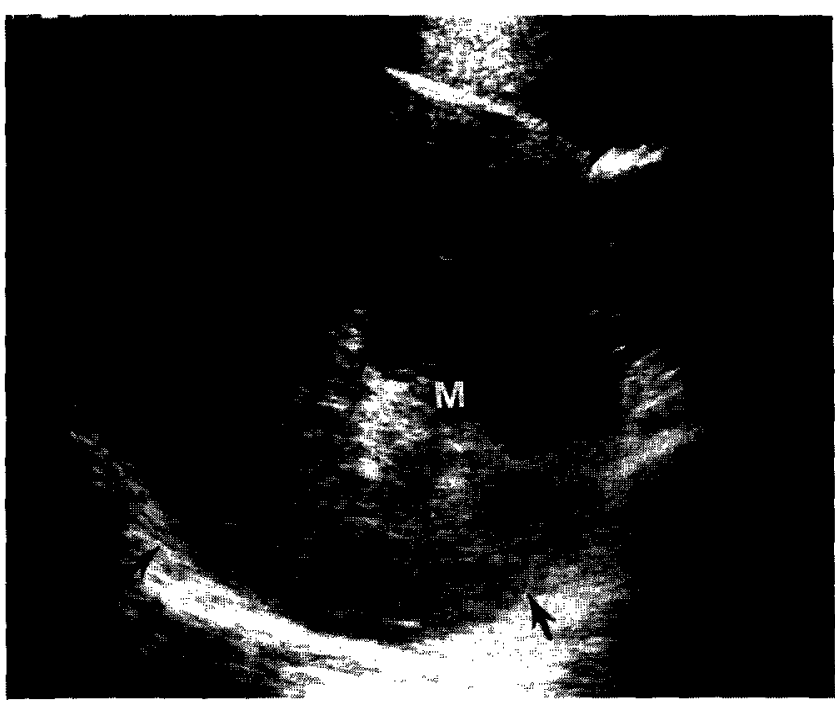

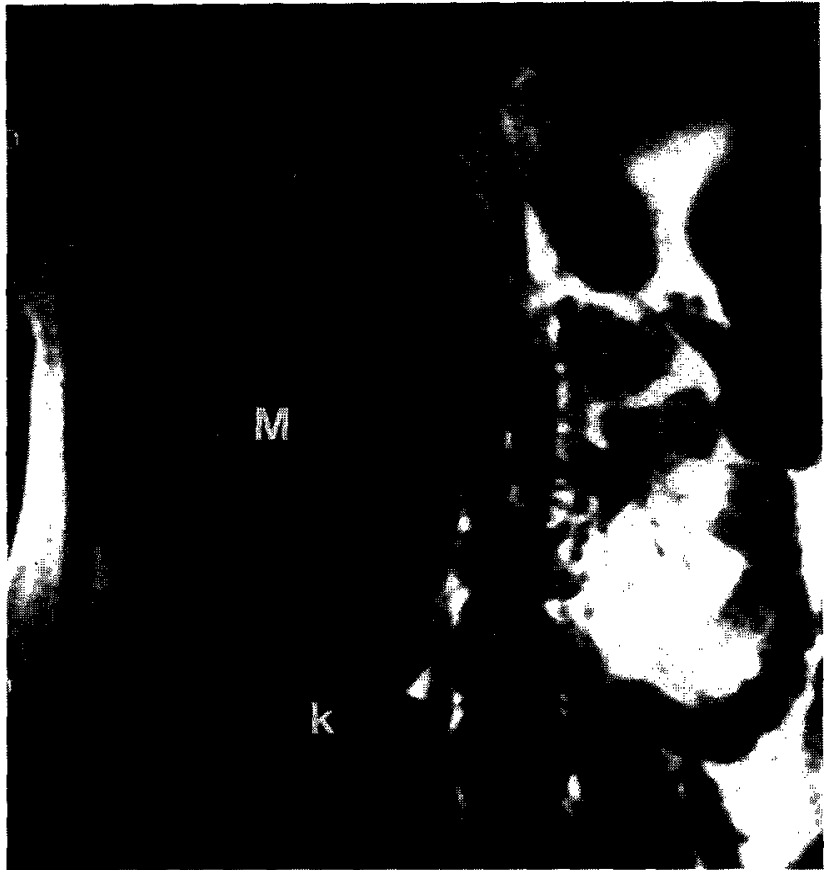

FIGURE 4. Coronal T1-weighted image demonstrates a low intensity mass $(\mathrm{M})$ which is contiguous with and involves the upper pole of the right kidney $(\mathrm{k})$.

strated on US. Soft tissue excrescences and septations were also seen within the mass on the T2-weighted images. (Figure $5 \mathrm{~A}$ and $\mathrm{B}$ ).

Differential considerations included adult Wilms' tumor, cystic hypernephroma, multilocular cystic nephroma, primary adrenal neoplasm with secondary renal involvement, or a retroperitoneal sarcoma.

Rapid expansion of the mass over the next three days caused symptoms of gastric obstruction. It was decided to proceed with surgical exploration and resection of the mass and simultaneous delivery of the infant. At surgery, a large retroperitoneal mass involving the upper pole of the right kidney, separate from the adrenal gland, was encountered. A radical right nephrectomy combined with tumor resection and lymph node dissection was carried out.

Pathologically, the tumor contained cystic and solid areas. The cystic component was $16 \mathrm{~cm}$ in length, containing fluid consistent with old hemorrhage. The solid portion replaced approximately $10 \%$ of the upper pole renal cortex. Histologic analysis including special stains demonstrated a round cell tumor identical to $\mathrm{Ew}$ ing's sarcoma. All nodes were negative for neoplasm. The final pathological diagnosis was a retroperitoneal extraosseous Ewing's sarcoma with secondary renal involvement. 


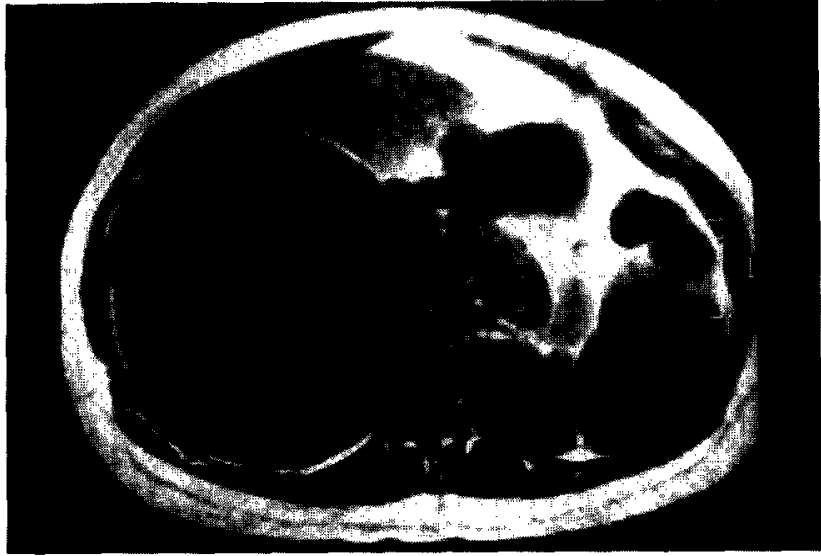

A

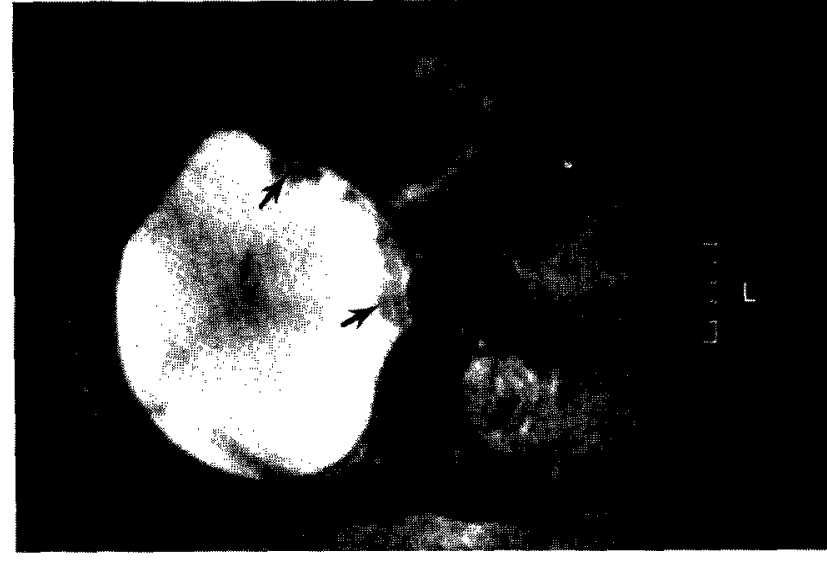

B

FIGURE 5. Axial T1 (A) and T2 (B) SE images. On the T2-weighted images note the high intensity cystic component, as well as soft tissue nodules (arrows) within the mass.

\section{DISCUSSION}

EES is a rare soft tissue neoplasm now generally accepted as a discrete pathological entity, based on histologic and electron microscopic features $(3,4,7-9)$. It can be differentiated from other rare soft tissue neoplasms such as primitive rhabdomyosarcoma and neuroectodermal tumors which may have some similar histologic features $(3,4,7-9)$.

Although EES can occur at any age, it most commonly is seen in the second and third decades $(4,5)$. There is a slight male preponderance. Common clinical presentations are a mass that may rapidly enlarge and can result in associated pain. However, depending on the site of occurrence, other clinical manifestations can result (4).

Stuart's review of the literature showed the most common sites of involvement to be the extremities (32\%), paravertebral (including epidural) $(15 \%)$, cervical $(11 \%)$, and the chest $(11 \%)(10)$.

On CT, the tumor generally is of low attenuation or has areas of lower attenuation than muscle (13). Enhanced CT may reveal necrosis or demonstrate peripheral enhancement (5), but no definite pattern of enhancement has been established. EES is hypoechoic or anechoic on ultrasound (13). Tumor hemorrhage is commonly found histologically and has been described on MRI (13). Because of its multiplanar capabilities and superior soft tissue definition, MRI has the greatest potential for evaluating EES.

Rarely, EES adjacent to bone may cause erosion and periosteal or cortical thickening. This may simulate the findings in osseous Ewing's, leading to misdiagnosis (2).

Common sites of metastases include the lung and the bones (5). Although metastases can be seen at pre- sentation, this was not true in our case. The tumor is an aggressive neoplasm with local recurrence being common (5).

Surgical resection followed by chemotherapy and local radiation therapy offers the best chance for long term survival. Disease free five-year survival rates of 63 to $87 \%$ have been reported using a combination of surgery with postoperative radiotherapy and multiagent chemotherapy $(11,12)$.

In conclusion, we report the US and MRI findings in a young patient with retroperitoneal EES and secondary involvement of the kidney. This tumor demonstrated cystic and solid components with areas of hemorrhage, but did not demonstrate any characteristic imaging features that could help to distinguish it from other retroperitoneal tumors. However, EES should be considered in the differential diagnosis of soft tissue tumors, especially in patients between the ages of 10 and 30 .

The authors wish to thank Heather Stites for assistance with manuscript preparation.

\section{REFERENCES}

1. Tefft M, Vawter GF, Mitus A. Paravertebral "round cell" tumors in children. Radiology 1969;92:1501-1509.

2. Angervall L, Enzinger FM. Extraskeletal neoplasm resembling Ewing's sarcoma. Cancer 1975;36:240-251.

3. Enzinger FM, Weiss SW. Soft Tissue Tumors. St. Louis: CV Mosby, 1983;801-808.

4. Rud NP, Reiman HM, Pritchard DJ, Frassica FJ, Smithson WA. Extraosseous Ewing's sarcoma. A study of 42 cases. Cancer $1989 ; 64: 1548-1553$.

5. Shirkhoda A, Peuchot M. Extraosseous Ewing's sarcoma. Com- 
puted tomography evaluation before and after chemotherapy. Clin Imay 1989;13:142-146.

6. Kamphorst W, van de Graaff M, van Alphen HA, Veerman AJ. Primary spinal epidural extraosseous Ewing's sarcoma. Cancer 1991;68:648-654.

7. Shimada H, Newton WA Jr, Soule EH, Qualman SJ, Aoyama C, Maurer HM. Pathologic features of extraosseous Ewing's sarcoma: A report from the Intergroup Rhabdomyosarcoma Study. Hum Pathol 1988;19:442-453.

8. Dickman PS, Triche TJ. Extraosseous Ewing's sarcoma versus primitive rhabdomyosarcoma: Diagnostic criteria and clinical correlation. Hum Pathol 1986;17:881-893.
9. Hoshimoto H, Tsuneyoshi M, Doimaru Y, et al. Extraskeletal Ewing's sarcoma. A clinico pathologic and electron microscopic analysis of 8 cases. Acta Pathol Jpn 1985;35:1087-1098.

10. Stuart RH. Eur J Cancer Clin Oncol 1986:22:393-400.

11. Ramey RB Jr, Ragab AH, Ruymann FB, et al. Soft tissue sarcoma of the trunk in childhood: Results of the Intergroup Rhabdomyosarcoma Study. Cancer 1982;49:2612-2616.

12. Hays DM, Doule EH, Lawrence W Jr, et al. Extremity lesions in the Intergroup Rhabdomyosarcoma Study (IRS-I). A preliminary report. Cancer 1982;49:1-8.

13. O'Keffe F, Lorigan JG, Wallace S. Radiological features of extraskeletal Ewing sarcoma. Br J Radiol 1990;63:456-460. 